\title{
Chronic diseases are not being managed effectively in either high-risk or low-risk populations in South Africa
}

M Brand, ${ }^{1}$ MB ChB, FCS (SA), MRCS, MMed (Surg); A J Woodiwiss, ${ }^{2} \mathrm{PhD}$; F Michel, ${ }^{2} \mathrm{PhD} ; \mathrm{H} \mathrm{L}$ Booysen, ${ }^{2} \mathrm{MSc}$; O H I Majane, ${ }^{2} \mathrm{PhD}$; M J Maseko, ${ }^{2}$ MSc; M G Veller, ${ }^{1}$ MB BCh, FCS (SA), MMed (Surg); G R Norton, ${ }^{2}$ MB ChB, PhD

${ }^{1}$ Department of Surgery, School of Medicine, Faculty of Health Sciences, University of the Witwatersrand, Johannesburg, South Africa

${ }^{2}$ Cardiovascular Pathophysiology and Genomics Research Unit, School of Physiology, Faculty of Health Sciences, University of the Witwatersrand, Johannesburg, South Africa

Corresponding author: M Brand (martinbrand78@gmail.com)

Background. Primary healthcare is the foundation of a country's healthcare system. Without an efficient and cost-effective programme, the level of healthcare offered across all levels of health management is adversely affected.

Objective. To analyse the effectiveness of the management of hypertension and diabetes mellitus (DM) among two distinct patient populations, one with significant cardiovascular risk factors and the other without.

Method. We performed a case control study of a high-risk group of patients presenting with chronic critical limb ischaemia (CLI) to the Divisions of Vascular Surgery at Charlotte Maxeke Johannesburg Academic Hospital and Chris Hani Baragwanath Academic Hospital, and a randomly selected group of 'healthy' community participants from Johannesburg's South Western Townships (Soweto).

Results. We assessed 217 patients with CLI and 1030 participants from the community. We assessed the number of patients who were not achieving their therapeuatic targets, among those known to be hypertensive (CLI: 44.7\%; community: 59.9\%) and diabetic (CLI: $83.5 \%$; community: $66 \%$ ). Undiagnosed diabetes affected $10.8 \%$ of patients with CLI and $11 \%$ of the community sample.

Conclusion. Traditional vascular risk factors are managed poorly at both primary healthcare and at tertiary care levels. There is a need to identify factors that will address this issue.

S Afr Med J 2013;103(12):938-941. DOI:10.7196/SAMJ.6018 


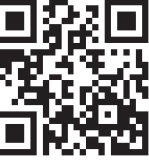

Groups of black African descent living in South Africa (SA) are a population on the brink of an epidemiological health transition. ${ }^{[1]}$ This population, which already bears a quadruple disease burden (HIV/AIDS; tuberculosis (TB); violence and injury; and poor maternal and child health) $)^{[2]}$ now faces an increasing prevalence of degenerative and lifestyle disease.

In 2008 the World Health Organization (WHO) emphasised that, especially in developing countries, effective primary healthcare (PHC) systems are essential to ensuring effective national healthcare. ${ }^{[3]}$ This is the challenge facing our already strained public health system, which is already hampered by lack of infrastructure, dwindling numbers of medical professionals and inadequate resources. Is there evidence that we are managing chronic diseases adequately, or is there room for improvement?

\section{Methods}

We performed a case-controlled crosssectional study in the Divisions of Vascular Surgery at Charlotte Maxeke Johannesburg Academic Hospital and Chris Hani Baragwanath Academic Hospital, Johannesburg, SA. We recruited consecutive patients referred with chronic critical limb ischaemia (CLI), defined as ischemic rest pain present for > 2 weeks; ulcers; or gangrene attributable to arterial occlusive disease. ${ }^{[4]}$

Using an existing database, 1030 participants were drawn from randomly selected families of black African descent (Nguni and Sotho chiefdoms) from Johannesburg's South Western Townships (Soweto) ${ }^{[5]}$ and enrolled as a control group. Only adults were recruited, with siblings older than 16 years. The database was the product of the African Project on Genes in Hypertension (APOGH). The APOGH group consists of randomly selected participants representing a community - some with hypertension, some diabetic, some with no comorbidities - and follows these patients over years to monitor disease progression and/or stability. Therefore, the APOGH group served as the ideal control group with which to compare a group of end-stage vascular disease patients.

The study was conducted according to the principles of the Declaration of Helsinki. The University of the Witwatersrand's Committee for Research on Human Subjects had previously approved the APGH protocol (approval number M02-04-72 and renewed as M07-04-69) as well as the current study (approval number M11-08-29). Participants gave written, informed consent.
A questionnaire obtained each participant's medical history, use of medication and smoking habits. Height and weight were measured with participants in a standing position, and body mass index (BMI) was calculated. A fasting lipid profile (cholesterol:high density lipoprotein (HDL) cholesterol ratio) and glycosylated haemoglobin (HbAlc) were measured as biochemical indicators of the risk factors of hyperlipidaemia and diabetes mellitus (DM).

Participants rested for 10 minutes in the supine position, after which 3 brachial blood pressure readings were obtained using an appropriately sized cuff. The mean of the 3 readings was calculated and used as the patient's blood pressure for that occasion. Hypertension was defined as either a systolic blood pressure $>130 \mathrm{mmHg}$ or diastolic blood pressure $>80 \mathrm{mmHg}$ in the CLI group, and either a systolic blood pressure $>140 \mathrm{mmHg}$ or diastolic blood pressure $>90 \mathrm{mmHg}$ in the community sample. Any patient taking anti-diabetic medication was considered to be diabetic.

Statistical analysis and database management were performed using SAS software version 9.3 Student $t$-tests were used to calculate $p$-values.

\section{Results}

\section{Participant characteristics}

A total of 217 patients with CLI were referred to our clinic, 78 (36\%) from secondary level facilities and 139 (64\%) from PHC clinics.

Table 1. Characteristics of participants

\begin{tabular}{|c|c|c|}
\hline & Community sample & CLI group \\
\hline Sample size, $N$ & 1030 & 217 \\
\hline Males, \% & 36 & $71^{*}$ \\
\hline Age (years), mean $\pm \mathrm{SD}$ & $43 \pm 18$ & $62 \pm 12^{*}$ \\
\hline Height $(\mathrm{cm})$, mean $\pm S D$ & $161 \pm 9$ & $170 \pm 10^{*}$ \\
\hline Body mass index $\left(\mathrm{kg} / \mathrm{m}^{2}\right)$, mean $\pm \mathrm{SD}$ & $28.5 \pm 7.3$ & $26.3 \pm 5.9^{*}$ \\
\hline Waist circumference $(\mathrm{cm})$, mean $\pm S D$ & $90.6 \pm 18.1$ & $83.8 \pm 21^{*}$ \\
\hline Obese, $\%$ & 39 & $18^{*}$ \\
\hline Hypertensive, \% & 42 & $62^{*}$ \\
\hline Receiving antihypertensives, $\%$ & 23 & $62^{*}$ \\
\hline With diabetes mellitus, \% & 8 & $45^{*}$ \\
\hline Current smoker, \% & 16 & $51^{*}$ \\
\hline Previous smoker, \% & 24 & $68^{*}$ \\
\hline Regular alcohol, \% & 22 & $57^{*}$ \\
\hline $\mathrm{BP}(\mathrm{mmHg})$, systolic/diastolic, mean $\pm \mathrm{SD}$ & $129 \pm 22 / 84 \pm 12$ & $137 \pm 21^{\star} / 80 \pm 12^{\star}$ \\
\hline Glycated haemoglobin (\%) & $6.07 \pm 1.31$ & $7.53 \pm 2.48^{\star}$ \\
\hline Total/HDL cholesterol & $3.49 \pm 1.24$ & $4.04 \pm 1.69^{*}$ \\
\hline
\end{tabular}

Table 1 shows the demographic and clinical characteristics of the study samples. Patients with CLI were, on average, older, suffered from concomitant DM, were smokers and used alcohol more frequently. The majority were males. Of the community sample more were obese, with a higher mean BMI; their total cholesterol:HDL cholesterol ratio was higher.

In the CLI group, 18 patients had suffered a previous ischemic coronary event and 9 had suffered a cerebrovascular accident. No participants in the community sample gave a significant cardiovascular or cerebrovascular history.

\section{Blood pressure}

Mean blood pressure was higher in the community sample, and both means were significantly higher than the recommended target blood pressure for their group. Table 2 shows the comparison of blood pressure control between the two groups for their respective targets. A total of 154 CLI patients were hypertensive, of whom 139 were on treatment, 28 with monotherapy and 111 with polytherapy. In the community sample 268 participants were on treatment, 180 with monotherapy and 88 with polytherapy.

\section{Glycaemic control}

In both the community sample and the CLI group with DM, the mean HbAlc was significantly higher $(>7.0 \%)$ (Table 2 ). In the CLI group, 97 patients were diagnosed with diabetes. In the control group, 103 
Table 2. Vascular risk factors and their therapeutic targets

\begin{tabular}{|c|c|c|}
\hline & Community sample & CLI group \\
\hline Hypertension, $n$ & 504 & 154 \\
\hline Therapeutic target & $140 / 90$ & $130 / 80$ \\
\hline $\begin{array}{l}\text { Blood pressure }(\mathrm{mmHg}) \text {, systolic/ } \\
\text { diastolic, mean } \pm \mathrm{SD}\end{array}$ & $144 \pm 23 / 91 \pm 13$ & $138.34 \pm 19 / 79.67 \pm 11$ \\
\hline SBP above therapeutic target, $n(\%)$ & $302(59.9)$ & $97(44.7)$ \\
\hline On therapy, $n$ & 268 & 139 \\
\hline Monotherapy & 180 & 28 \\
\hline Polytherapy & 88 & 111 \\
\hline Diabetes, ${ }^{*} n$ & 103 & 97 \\
\hline $\mathrm{HbAlc}$, mean $\pm \mathrm{SD}$ & $8.84 \pm 2.78$ & $9.36 \pm 2.52$ \\
\hline HbAlc above therapeutic target, $n(\%)$ & $68(66.0)$ & $81(83.5)$ \\
\hline Oral therapy alone, $n$ & 76 & 59 \\
\hline Insulin/combined therapy, $n$ & 27 & 38 \\
\hline Serum lipids, ${ }^{\dagger} n$ & 430 & 217 \\
\hline Triglycerides $(\mathrm{mmol} / \mathrm{L})$, mean $\pm \mathrm{SD}$ & $1.16 \pm 0.66$ & $1.36 \pm 0.65$ \\
\hline $\mathrm{LDL}(\mathrm{mmol} / \mathrm{L})$, mean $\pm \mathrm{SD}$ & $2.65 \pm 0.90$ & $2.18 \pm 0.97$ \\
\hline $\mathrm{HDL}(\mathrm{mmol} / \mathrm{L})$, mean $\pm \mathrm{SD}$ & $1.41 \pm 0.45$ & $1.10 \pm 0.46$ \\
\hline Total cholesterol/HDL ratio, mean \pm SD & $3.49 \pm 1.17$ & $4.04 \pm 1.69$ \\
\hline HIV-positive, $n$ & Not measured & 25 \\
\hline $\mathrm{CD} 4^{+}$count $\leq 350$ cells $/ \mu \mathrm{l}$, mean $\pm \mathrm{SD}$ & Not measured & 15 \\
\hline $\mathrm{CD} 4^{+}$count, $>350$ cells $/ \mu \mathrm{l}$, mean $\pm \mathrm{SD}$ & Not measured & $331.43 \pm 84.1$ \\
\hline \multicolumn{3}{|c|}{$\begin{array}{l}\mathrm{CLI}=\text { Critical limb ischemia; } \mathrm{SD}=\text { standard deviation; } \mathrm{SBP}=\text { systolic blood pressure; } \mathrm{HbAlc}=\text { glycosylated haemoglobin; } \\
\mathrm{LDL}=\text { low-density lipoprotein; } \mathrm{HDL}=\text { high-density lipoprotein. } \\
\text { Therapeutic target: } \mathrm{HbAlc}<7.0 \% \\
\text { Triglyceride }<1.7 \mathrm{mmol} / \mathrm{l}, \mathrm{LDL}<3.0 \mathrm{mmol} / \mathrm{l}, \mathrm{HDL}>1.03 \text { (males), }>1.29 \text { (females) }\end{array}$} \\
\hline
\end{tabular}

participants were diagnosed with diabetes. Only 35 (34.0\%) patients in the community sample and 16 (16.5\%) in CLI group diagnosed with DM appeared to have achieved their $\mathrm{HbAlc}$ therapeutic target. Of the 927 patients in the community sample who did not have DM, 102 (11.0\%) had an $\mathrm{HbAlc}>7.0 \%$. Of the 120 patients with CLI who were not diagnosed with DM, 13 (10.8\%) had an HbAlc $>7.0 \%$.

\section{Serum lipids}

No patient in either sample was known to have hypercholesterolaemia (Table 2). All patients in the CLI group were on a statin as a component of their peripheral arterial disease management and their cholesterol levels were within accepted ranges.

\section{Smoking}

There was a high prevalence of smoking. The CLI group were more likely to smoke, but the amount smoked was low (Table 1). Indeed, for many the amount smoked was too irregular to calculate a daily average, many patients smoking <5 cigarettes/day. Both groups demonstrated a decrease in smoking from previous smoking, but current smoking levels remained significant.

\section{Discussion}

We have studied risk factors for vascular disease and their management in patients with severe peripheral arterial disease, as well as in a randomly selected community sample. In SA, only $14-40 \%$ of patients $50 \%$ of diabetics currently achieve glucose control. ${ }^{[6,7]}$ Our data was in line with these studies for our group of patients at high risk for adverse cardiovascular events. Blood pressure and glycaemic control is poor in both groups but significantly worse in the CLI group. We have also shown that approximately $10 \%$ of the population have not had their DM diagnosed and may present to hospitals with complications of their disease, such as CLI. Blood pressure and $\mathrm{HbAlc}$ values for the community sample are in keeping with other general SA community samples, as is their use of medication. ${ }^{[8,9]}$ The community sample was significantly more overweight than the CLI group, in keeping with other SA studies..$^{[9,10]}$ achieve blood pressure control and 16 -
In $\mathrm{SA}$, clinical nurse practitioners are the main primary healthcare providers. From our study and several other community based studies in various provinces, ${ }^{[6,9-11]}$ it appears that the current healthcare system is failing to serve the greater public. SA is not the only country in which nurse-led PHC has not succeeded. In 2000 the Japanese instituted a nurse-led PHC initiative called 'Kenko-Nippon-21' (Healthy Japan 21). ${ }^{[12]}$ An audit of its treatment effects in 2004 showed that some outcomes for the population involved had worsened instead of improving. ${ }^{[8]}$ In response, the Japanese began a new screening and intervention programme that identified individuals at risk, who were then referred to a doctorsupervised counselling or intervention programme. ${ }^{[8]} \mathrm{PHC}$ should be doctor-led to improve quality of care. ${ }^{[13,14]}$

DM management can be significantly improved, even in resource-poor environments, through physician-patient contact, with up to $85 \%$ of patients achieving their glucose targets in diabetes-focused PHC clinics. ${ }^{[15]}$ The initiation and ongoing use of insulin is a stumbling block in non-hospital clinics, and non-specialist nurses cannot be expected to commence or monitor this therapy ${ }^{[16,17]}$ On the other hand, specialist diabetic nurses working in PHC clinics do help patients achieve therapeutic targets. ${ }^{[17]}$

In Germany, disease-management programmes started in the 1990s and are run as secondary prevention programmes. Diagnosed patients are entered into specialist-led disease programmes in their area. ${ }^{[18]}$ This system has been shown to be effective and economical over the long term. ${ }^{[19]}$ Brazil has significantly improved its PHC system by developing a family-health programme, which runs clinics staffed by a doctor and nurse and linked to other clinics and regional medical centres through a comprehensive health-management information system. ${ }^{[20]}$ In situations where there are no doctors, nurse-led clinics have led to improvement in diabetic and hypertensive parameters, thanks to the information system and clear referral pathways to regional medical centers. While the values did not fall within recognised therapeutic targets, improvements did reach statistical significance. ${ }^{[2]]}$

The SA Government's Primary Healthcare Services Package was designed to create 'one-stop public healthcare' with a view to decreasing the burden on hospitals. ${ }^{[22]}$ It is evident from our study, as well as other community studies, that this policy has failed. If SA is to decentralise PHC, 
polyclinics with specialist nurses in chronic diseases such as DM and hypertension should be created.

Medical care in SA remains hospicentric. ${ }^{[1,23]}$ Though there are initiatives in place to alleviate the burden on hospitals (such as the National Strategic Plan on HIV, sexually transmitted infections and TB 2012 - 2016, which was launched on 1 April 2012, ${ }^{[23]}$ and the proposed National Health Insurance (NHI) scheme), it will be several years before they come to fruition. In the meantime, hospital doctors should take every opportunity to provide PHC, and must not assume that patients will automatically receive it outside their hospital. A patient who is admitted for an inguinal hernia repair who is hypertensive and diabetic should have their blood pressure and diabetic management carefully evaluated before discharge. Upon discharge, doctors must carefully consider whether PHC or short-term hospital out-patient follow-up is appropriate for that specific patient. Once their comorbidities are well-controlled patients can be managed peripherally, with clear channels and protocols of referral back to the specialist clinic should the need arise. Widespread specialist nurse-led polyclinics could supplement the current PHC system by acting as an intermediate step to tertiary care.

\section{Conclusion}

We have demonstrated poor cardiovascular risk-factor management in high-risk and low-risk patient cohorts in Gauteng, both at tertiary and primary care levels. Review of the SA literature highlights the defects of the PHC system. In improving PHC in SA, efforts should be made to learn from other PHC systems, such as the Japanese, German and Brazilian systems. The district clinical specialist teams that are planned for under the forthcoming NHI system may promote improved cardiovascular disease prevention and management. Until then, however, every patient encounter at any level of care should be considered an opportunity to prevent or manage chronic illnesses.

Acknowledgements. This work was supported by the SA Medical Research Council, the Circulatory Disorders Research Trust, the University Research Council of the University of the Witwatersrand, the SA National Research Foundation, and the Carnegie Trust. MB is a recipient of a Carnegie Clinical Fellowship.

\section{References}

1. Tollman SM, Kahn K, Sartorius B, et al. Implications of mortality transition for primary healthcare in rural South Africa: A population-based surveillance study. Lancet 2008;372(9642):893-901. [http:// dx.doi.org/10.1016/S0140-6736(08)61399-9]

2. Coovadia H, Jewkes R, Barron P, Sanders D, McIntyre D. The health and health system of South Africa: Historical roots of current public health challenges. Lancet 2009;374(9692):817-834. [http://dx.doi. org/10.1016/S0140-6736(09)60951-X]

3. World Health Organization. The World Health Report 2008 - Primary Health Care: Now More Than Ever. Geneva: WHO, 2008.

4. Rutherford RB, Baker JD, Ernst C, et al. Recommended standards for reports dealing with lower extremity ischemia: Revised version. J Vasc Surg 1997;26(3):517-538.

5. Shiburi CP, Staessen JA, Maseko M, et al. Reference values for SphygmoCor measurements in 5. Shiburi CP, Staessen JA, Maseko M, et al. Reference values for SphygmoCor measurements in
South Africans of African ancestry. Am J Hypertens 2006;19(1):40-46. [http://dx.doi.org/10.1016/j. amjhyper.2005.06.018]

6. Rotchford AP, Rotchford KM. Diabetes in rural South Africa - an assessment of care and complications. S Afr Med J 2002;92(7):536-541.

7. Levitt NS, Bradshaw D, Zwarenstein MF, Bawa AA, Maphumolo S. Audit of public sector primary diabetes care in Cape Town, South Africa: High prevalence of complications, uncontrolled hyperglycaemia, and hypertension. Diabet Med 1997;14(12):1073-1077.

8. Kohro T, Furui $\mathrm{Y}$, Mitsutake $\mathrm{N}$, et al. The Japanese national health screening and intervention program aimed at preventing worsening of the metabolic syndrome. Int Heart J 2008;49(2):193-203.

9. Thorogood M, Connor M, Tollman S, et al. A cross-sectional study of vascular risk factors in a rural South African population: Data from the Southern African Stroke Prevention Initiative (SASPI). BMC Public Health 2007;7:326. [http://dx.doi.org/10.1186/1471-2458-7-326]

10. Hall V, Thomsen RW, Henriksen O, Lohse N. Diabetes in sub-Saharan Africa 1999-2011: Epidemiology and public health implications. A systematic review. BMC Public Health 2011;11:564. [http://dx.doi.
and

org/10.1186/1471-2458-11-564]
11. Mash B, Fairall L, Adejayan O, et al. A morbidity survey of South African primary care. PLoS One 2012;7(3):e32358. [http://dx.doi.org/10.1371/journal.pone.0032358]

12. Kenko-Nippon-21. http://www.kenko-nippon21 forum.gr.jp (accessed 2 May 2012).

13. van Zyl DG, Rheeder P. Physician education programme improves quality of diabetes care. S Afr Med J 2004;94(6):455-459.

14. Oosthuizen H, Riedijk R, Nonner J, Rheeder P, Ker JA. An educational intervention to improve the quality of care of diabetic patients. S Afr Med J 2002;92(6):459-464.

15. Mshelia DS, Akinosun OM, Abbiyesuku FM. Effect of increased patient-physician contact time and health education in achieving diabetes mellitus management objectives in a resource-poor environment. Singapore Med J 2007;48(1):74-79.

16. Haque M, Emerson SH, Dennison CR, Navsa M, Levitt NS. Barriers to initiating insulin therapy in patients with type 2 diabetes mellitus in public-sector primary healthcare centres in Cape Town. S Afr Med J 2005;95(10):798-802.

17. Jeavons D, Hungin APS, Cornford CS. Patients with poorly controlled diabetes in primary care: Healthcare clinicians' beliefs and attitudes. Postgrad Med J 2006;82(967):347-350. [http://dx.doi. org/10.1136/pgmj.2005.039545]

18. Stock SA, Redaelli M, Lauterbach KW. Disease management and healthcare reforms in Germany - does more competition lead to less solidarity? Health Policy 2007;80(1):86-96. [http://dx.doi. org/10.1016/j.healthpol.2006.02.005]

19. Szecsenyi J, Rosemann T, Joos S, Peters-Klimm F, Miksch A. German diabetes disease management programs are appropriate for restructuring care according to the chronic care model: An evaluation with the patient assessment of chronic illness care instrument. Diabetes Care 2008;31(6):1150-1154. [http://dx.doi.org/10.2337/dc07-2104]

20. Macinko J, Almeida C, dos SE, de Sá PK. Organization and delivery of primary healthcare services in Petrópolis, Brazil. Int J Health Plann Manage 2004;19(4):303-317. [http://dx.doi.org/10.1002/ hpm.766]

21. Kengne AP, Fezeu L, Sobngwi E, et al. Type 2 diabetes management in nurse-led primary healthcare settings in urban and rural Cameroon. Primary Care Diabetes 2009;3(3):181-188.

22. Heunis JC, van Rensburg HC, Claassens DL. Assessment of the implementation of the primary healthcare package at selected sites in South Africa. Curationis 2006;29(4):37-46.

23. The Lancet. South Africa’s AIDS response: The next 5 years. Lancet 2012;379(9824):1365-1366 